\title{
Vitexin induces G2/M-phase arrest and apoptosis via Akt/mTOR signaling pathway in human glioblastoma cells
}

\author{
GUANGNING ZHANG ${ }^{1}$, DONGYUAN $\mathrm{LI}^{2}, \mathrm{HAO} \mathrm{CHEN}^{1}$, JUNCHEN ZHANG ${ }^{1}$ and XINGYI JIN ${ }^{2}$ \\ ${ }^{1}$ Department of Neurosurgery, Affiliated Hospital of Jining Medical University, Jining, Shandong 272000; \\ ${ }^{2}$ Department of Neurosurgery, China-Japan Union Hospital of Jilin University, Changchun, Jilin 130033, P.R. China
}

Received July 26, 2017; Accepted October 24, 2017

DOI: $10.3892 / \mathrm{mmr} .2018 .8394$

\begin{abstract}
Glioblastoma is a common primary brain tumor with aggressive malignancy, which results in poor outcomes, short survival time and high mortality. Vitexin, an active ingredient from natural products, has been reported to inhibit cell growth and induce cell apoptosis in various cancer cell lines including hepatocellular carcinoma, oral and esophageal cancer. To the best of the authors knowledge, the present study was the first to investigate anticancer effects of vitexin on human glioblastoma cells and potential underlying mechanisms. The present study demonstrated that vitexin inhibited cell viability in a dose- and time-dependent manner. In the present study, vitexin induced G2/M cell cycle arrest, as demonstrated by flow cytometry. Induction of cell apoptosis following vitexin treatment, was further indicated by observation of morphological alterations, flow cytometry analysis and detection of cleaved-poly (ADP-ribose) polymerase. The present study also demonstrated that vitexin inhibited RAC-alpha serine/threonine-protein kinase (Akt)/mechanistic target of rapamycin kinase (mTOR) signaling in human glioblastoma cells. Collectively, the results of the present study demonstrated that vitexin induced G2/M cell cycle arrest and apoptosis by inhibiting Akt/mTOR signaling in human glioblastoma cells. Vitexin may in the future be used as a therapeutic agent for treatment of malignant glioblastoma.
\end{abstract}

\section{Introduction}

Glioblastoma (GBM), a common primary malignant brain tumor, accounts for $70 \%$ of total brain tumors and demonstrates aggressive proliferation, metastasis and recurrence (1-3). These biological behaviors contribute to its poor prognosis and high mortality with $15-20 \%$ patients surviving $>3$ months post-diagnosis $(4,5)$. Due to simultaneous occurrence of

Correspondence to: Dr Xingyi Jin, Department of Neurosurgery, China-Japan Union Hospital of Jilin University, 126 Xiantai Road, Changchun, Jilin 130033, P.R. China

E-mail: jin5756@163.com

Key words: vitexin, G2/M-phase arrest, apoptosis, signaling pathway, glioblastoma multiple lesions, it is challenging to treat patients with GBM and obtain a desirable clinical outcome (6). At present, a clinical therapeutic regimen for patients with GBM is to coordinate several methods including neurosurgery, radiotherapy and chemotherapy (7). Despite the progress made in these treatment methods, the outcome for patients with GBM remains poor due to disease recurrence, with 12-15 months median survival time (8). Therefore, there is a need to investigate more effective therapies targeting aggressive biological processes associated with GMB to improve prognosis.

Vitexin, an apigenin-8-C-D-glucopyranoside, is a flavonoid compound derived from natural products, serving the role of active ingredient in a number of traditional Chinese medicines $(9,10)$. Numerous studies have demonstrated that vitexin has anti-oxidative, anti-inflammatory, anti-hyperalgesic and neuroprotective effects (11-14). It has also been reported that vitexin may suppress cell growth and induce cell apoptosis in a number of cancer cell lines including hepatocellular carcinoma, oral and esophageal cancer (15-17). However, to the best of the authors knowledge, whether vitexin exhibits an effect on GBM remains to be elucidated.

Cell proliferation requires completion of a cell cycle, and cell apoptosis results from cell cycle arrest (18). A complete cell cycle is composed of G1, S, G2 and M phases, in which a successful G2/M transition is important. It has been previously demonstrated that uncontrolled cell proliferation is a consequence of imbalanced cell cycle regulation, which is a characteristic of cancer cells $(19,20)$. Numerous anticancer drugs have been reported to induce G2/M cell cycle arrest which may effectively repress proliferation of cancer cells (21-23).

Apoptosis, also known as type I programmed cell death, is a regulated process triggered in response to cell damage (24). It is primarily triggered by caspase-dependent intrinsic or extrinsic pathways and may be predictive factor for the cytotoxicity of anti-cancer drugs (25). During apoptosis, a characteristic morphological alteration in cells is observed, including cell shrinkage, chromatin condensation and nuclear fragmentation (26). Additionally, poly(ADP-ribose) polymerase (PARP), a component of the DNA damage response mechanism elicited by cytotoxic agents, is cleaved by functional caspases activated in the apoptotic process (27). Phosphatidylinositol 4,5-bisphosphate 3-kinase (PI3K)/RAC- $\alpha$ serine/threonine-protein kinase (Akt)/mechanistic target of rapamycin kinase (mTOR) signaling pathway 
is a common cancer-associated pathway and previous studies have reported that it is negatively associated with cell apoptosis in various cancers (28-30).

To the best of the authors knowledge, the present study was the first to investigate the anti-cancer effect of vitexin on human GBM cells and to attempt to elucidate the underlying mechanisms. The present study demonstrated that vitexin induced G2/M cell cycle arrest and cell apoptosis by inhibiting Akt/mTOR signaling in human GBM cells.

\section{Materials and methods}

Cell line and culture. The human GBM cell line LN-18 was purchased from American Type Culture Collection (ATCC; Manassas, VA, USA). These cells were cultured in Dulbecco's modified Eagle's medium (DMEM) supplemented with $10 \%$ fetal bovine serum (FBS), $1 \%$ penicillin $(100 \mathrm{U} / \mathrm{ml})$ and $1 \%$ streptomycin $(100 \mu \mathrm{g} / \mathrm{ml})$. The culture was maintained at $37^{\circ} \mathrm{C}$, in a humid atmosphere containing $5 \% \mathrm{CO}_{2}$.

Reagents. DMEM and FBS were acquired from Gibco (Thermo Fisher Scientific, Inc., Waltham, MA, USA). Vitexin was purchased from Selleck Chemicals (Houston, TX, USA) and stored at $-20^{\circ} \mathrm{C}$ following preparation of the stock solution at $300 \mathrm{mM}$ vitexin dissolved in dimethyl sulfoxide (Sigma-Aldrich; Merck KGaA, Darmstadt, Germany). Antibodies against cleaved-PARP (cat. no. 5625), Akt (cat. no. 4685), mTOR (cat. no. 2983), phosphor (p)-Akt (cat. no. 4060), p-mTOR (cat. no. 5536), GAPDH (cat. no. 5174) and anti-rabbit immunoglobulin $\mathrm{G}$, horseradish peroxidase-linked antibody (cat. no. 14708) were purchased from Cell Signaling Technology, Inc. (Danvers, MA, USA).

Cell viability assay. Viability of GBM cells following treatment with vitexin was assessed using Cell Counting Kit-8 (CCK8; Dojindo Molecular Technologies, Inc., Kumamoto, Japan). Cells were plated in 96-well plates at a density of $5 \times 10^{5}$ cells $/ \mathrm{ml}$ for $24 \mathrm{~h}$ and subsequently treated with different concentrations of vitexin $(0,10,20,40,80$ and $160 \mu \mathrm{M})$. Following incubation for another 24 or $48 \mathrm{~h}$ at $37^{\circ} \mathrm{C}$, cells were washed with PBS twice and cultured with CCK8 solution for $2 \mathrm{~h}$ according to the manufacturer's instructions. The absorbance was measured at a wavelength of $450 \mathrm{~nm}$ using a microplate reader iMark (Molecular Devices, LLC, Sunnyvale, CA, USA) and $\mathrm{IC}_{50}$ values were calculated using SPSS software 19.0 statistical software package (IBM Corp., Armonk, NY, USA).

Cell cycle analysis by flow cytometry. The influence of vitexin on the proportion of cells at differing stages of the cell cycle was examined using flow cytometry. Cells were plated in a 6 -well plate at a density of $5 \times 10^{6}$ cells $/ \mathrm{ml}$ and treated with different concentrations of vitexin $(0,20,40$ and $80 \mu \mathrm{M}$ ) for $24 \mathrm{~h}$ at $37^{\circ} \mathrm{C}$. Cells were digested using trypsin at $37^{\circ} \mathrm{C}$ for $1 \mathrm{~min}$ and centrifuged at $600 \mathrm{x} \mathrm{g}$ for 5 min at room temperature following washing with $\mathrm{PBS}$, fixed in $75 \%$ ethanol at $4^{\circ} \mathrm{C}$ overnight and subsequently stained with propidium iodide assay kit (BD Biosciences, Franklin Lakes, NJ, USA) for $15 \mathrm{~min}$ in the dark. The cell cycle distribution was analyzed using an Accuri C6 flow

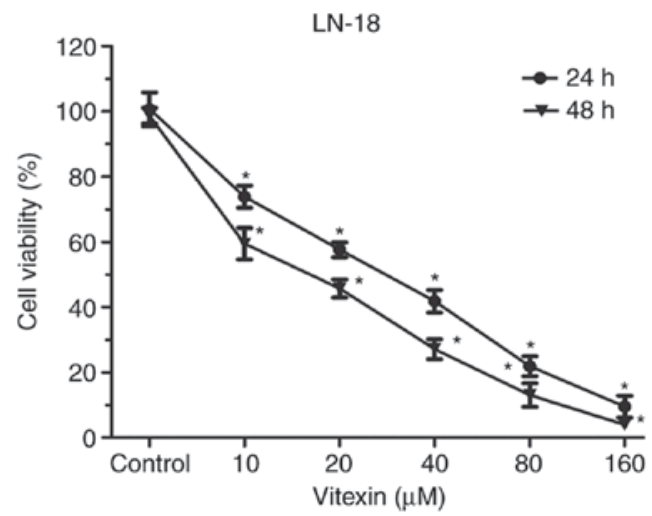

Figure 1. Vitexin inhibits cell viability of human GBM cells. Human GBM cells were treated with vitexin $(0,10,20,40,80$ and $160 \mu \mathrm{M})$ for 24 or $48 \mathrm{~h}$. The effect of vitexin on viability of GBM cells was determined by using Cell Counting Kit-8. Data are presented as the mean \pm standard deviation. ${ }^{*} \mathrm{P}<0.05$ vs. the untreated control group. GBM, glioblastoma.

cytometer (BD Biosciences) and the resulting data were presented following analysis with ModFit LT software v3.1 (FACSCalibur; BD Biosciences).

Morphological apoptosis. Morphological characteristics of apoptotic cells were observed using Hoechst 33342 staining. Cells were incubated in 6-well plates with a coverslip at a density of $5 \times 10^{6}$ cells $/ \mathrm{ml}$ and treated with $40 \mu \mathrm{M}$ vitexin for $24 \mathrm{~h}$ at $37^{\circ} \mathrm{C}$. Following incubation, cells on the coverslip were washed with PBS three times and fixed in $4 \%$ paraformaldehyde for $20 \mathrm{~min}$ at room temperature and washed again with PBS. Subsequently, $0.1 \%$ Triton X-100 was used to permeabilize the cells and Hoechst 33342 solution $(5 \mu \mathrm{g} / \mathrm{ml})$ was added to stain the nucleus of apoptotic cells, for $10 \mathrm{~min}$ at room temperature without light. A fluorescence microscope (Olympus Corporation, Tokyo, Japan) was used to observe morphological alterations in the stained cells.

Flow cytometric analysis of apoptosis. Apoptosis detection was identified using a Annexin V-fluorescein isothiocyanate (FITC)/PI assay kit (Beyotime Institute of Biotechnology, Beijing, China) according to the manufacturer's instructions. In brief, the GBM cells were incubated in 6-well plates at a density of $5 \times 10^{6}$ cells $/ \mathrm{ml}$ and treated with $0,20,40$ and $80 \mu \mathrm{M}$ vitexin. Following incubation for $24 \mathrm{~h}$ at $37^{\circ} \mathrm{C}$ and two washes in ice-cold PBS, cells were collected and re-suspended in annexin-binding buffer. Subsequently, cells were stained by adding Annexin V-FITC and PI at room temperature for 15 min without light. Apoptosis analysis of each sample was performed using an flow cytometer with Accuri C6 software (BD Biosciences).

Western blotting. Protein samples were extracted by adding radioimmunoprecipitation assay buffer (Sigma-Aldrich; Merck KGaA) to lyse GBM cells. Protein concentrations were quantified using a Bicinchoninic Acid Protein Assay kit (Pierce; Thermo Fisher Scientific, Inc.) according to the manufacturer's instructions. Proteins, $30 \mu \mathrm{g} /$ lane, were added and separated on 8-12\% SDS-PAGE prior to being transferred onto polyvinylidene fluoride membranes (EMD Millipore, Billerica, MA, USA). Subsequently, membranes were blocked 

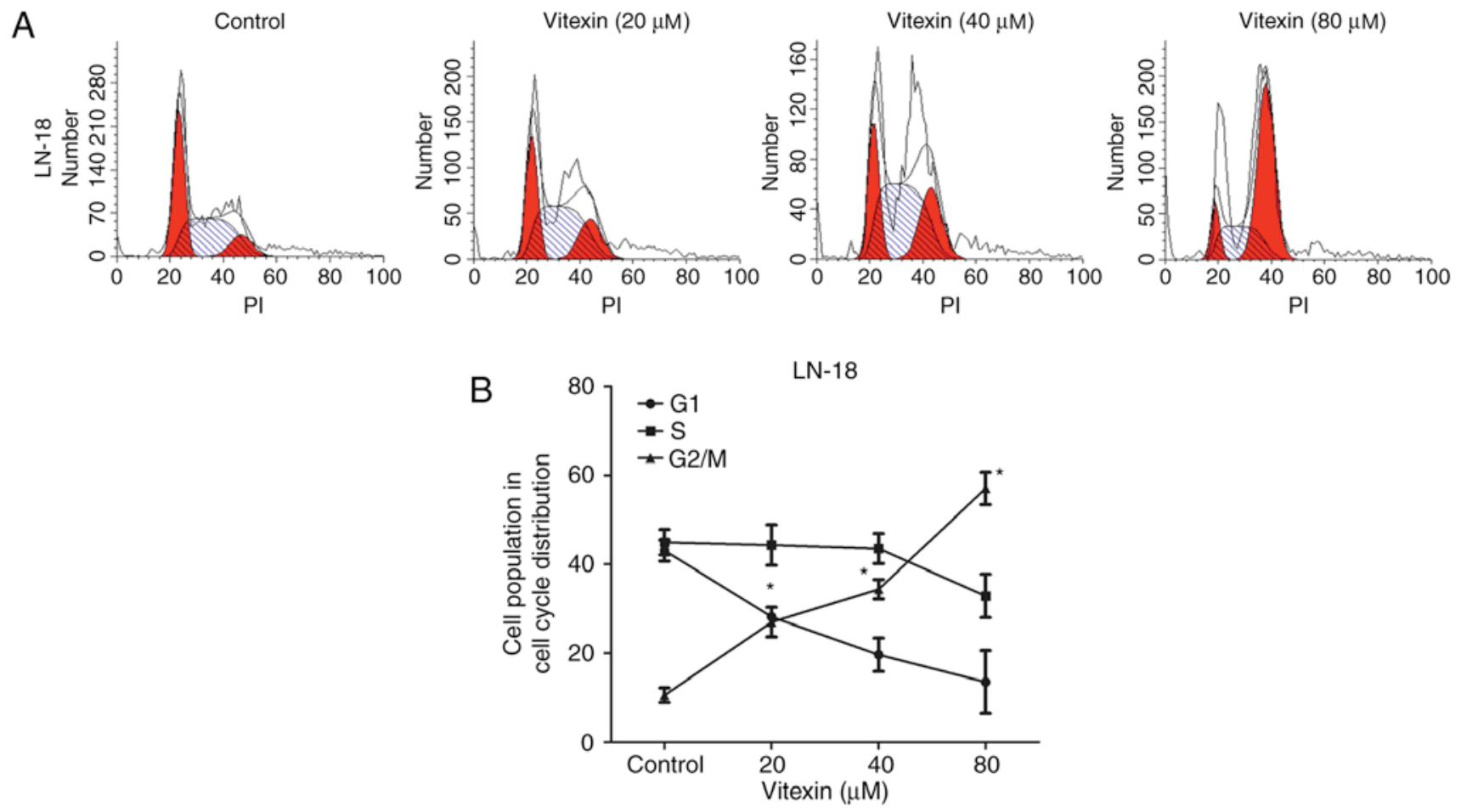

Figure 2. Vitexin induces G2/M cell cycle arrest in human GBM cells. Human GBM cells were treated with vitexin at $0,20,40$ and $80 \mu \mathrm{M}$ for 24 h. Following incubation, cells were harvested and cell cycle distribution was analyzed by flow cytometry. (A) Vitexin led to the accumulation of cells in G2/M phase (first red peaks) and a corresponding decrease in G0/G1 (the second red peaks). The number of cells in the S phase (blue stripes) did not significantly change; however, a marked increase was observed in response to $40 \mu \mathrm{M}$. (B) A line chart presenting the significant increase of the cell population in the G2/M phase (from 40.3 to $17.7 \%$ ), and the decrease in the G1 phase (from 14.0 to $52.5 \%$ ). Data are presented as the mean \pm standard deviation. "P<0.05 vs. the untreated control group. GBM, glioblastoma; PI, propidium iodide.

using 5\% skimmed milk at room temperature for $1 \mathrm{~h}$. Primary antibodies (1:1,000; cleaved-PARP, Akt, phospho-Akt, mTOR, phospho-mTOR and GAPDH) were added to the membranes and incubated at $4^{\circ} \mathrm{C}$ overnight. Subsequently, horseradish peroxidase-conjugated secondary antibody $(1: 5,000)$ was added for $1 \mathrm{~h}$ at room temperature. Detection of proteins was performed using an Enhanced Chemiluminescence kit (EMD Millipore).

Statistical analysis. Data are presented as the mean \pm standard deviation of three independent experiments and analyzed by one-way analysis of variance and Dunnett's post hoc test were used in order to compare differences among groups. $\mathrm{P}<0.05$ was considered to indicate a statistically significant difference. All statistical analyses were performed using SPSS software (version 18.0; SPSS, Inc., Chicago, IL, USA).

\section{Results}

Vitexin inhibits cell viability in human GBM cells. The influence of vitexin on proliferation of human GBM cells was assessed by CCK- 8 assay (Fig. 1). Cells were cultured with different concentrations of vitexin $(0,10,20,40,80$ and $160 \mu \mathrm{M}$ ) for 24 or $48 \mathrm{~h}$. Following incubation, cell viability significantly decreased in a dose and time dependent manner. $\mathrm{IC}_{50}$ values for GBM cells were 32.32 and $25.32 \mu \mathrm{M}$ following 24 and $48 \mathrm{~h}$ of incubation, respectively. The aforementioned results indicated that vitexin suppressed cell proliferation in human GBM cells in a dose- and time-dependent manner.
Vitexin induces G2/M cell cycle arrest in human GBM cells. To investigate whether vitexin inhibited GBM cell proliferation by inducing cell cycle arrest, cell cycle progression was assessed by flow cytometry. Following treatment with vitexin at 20-80 $\mu \mathrm{M}$ for $24 \mathrm{~h}$, cells were collected to perform cell cycle analysis (Fig. 2A and B). Compared with the control group, a significant increase in the percentage of the cell population in the $\mathrm{G} 2 / \mathrm{M}$ phase, and a decrease in the number of cells in G1 phase, were observed in cells treated with vitexin. The aforementioned data indicated that vitexin exhibited an effect on cell cycle progression by inducing cell cycle arrest at G2/M phase.

Vitexin induces apoptosis in human GBM cells. Cell apoptosis is a consequence of cell cycle arrest. Therefore, the present study further investigated the influence of vitexin on cell apoptosis of human GBM cells. Hoechst 33258 staining was performed to observe nuclear morphological alterations characteristic of apoptotic cells, following treatment of GBM cells with $40 \mu \mathrm{M}$ vitexin for $24 \mathrm{~h}$. GBM cells treated with vitexin exhibited features including cell shrinkage, chromatin condensation and nuclear fragmentation, compared with the control group (Fig. 3A). Subsequently, Annexin V/PI double staining was used to assess the proportion of apoptotic cells. The results indicated a dose-dependent increase in the number of early and late apoptotic cells (Fig. 3B and C). Western blotting was performed to determine the expression level of the intracellular apoptosis-associated protein, cleaved-PARP. PARP recruits DNA repair proteins by binding to DNA 
A
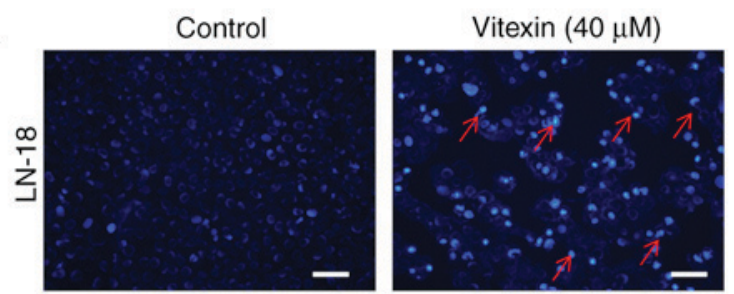

B
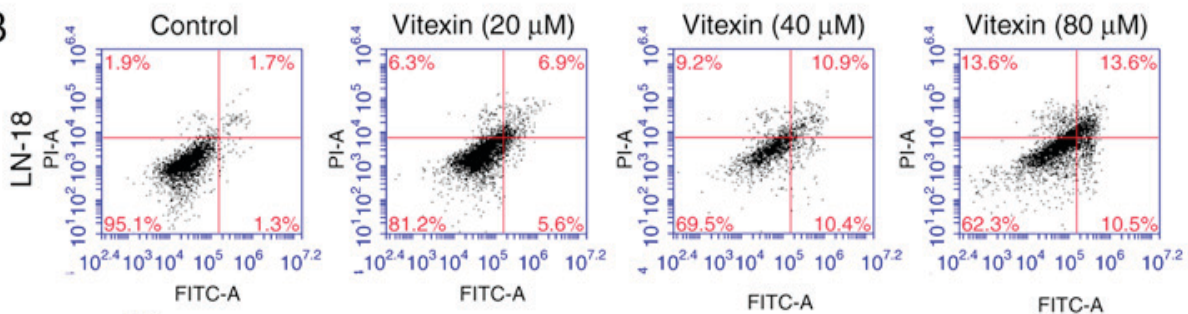

C

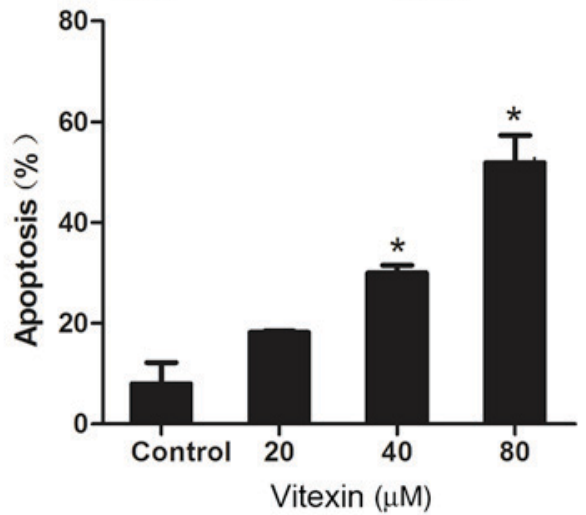

D

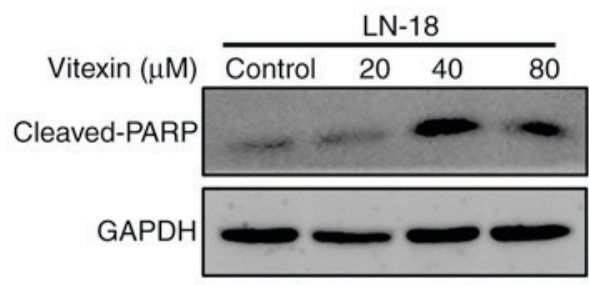

Figure 3. Vitexin induces apoptosis of human GBM cells. GBM cells were treated with vitexin for $24 \mathrm{~h}$. (A) Nuclear morphological alterations characteristic of apoptotic cells (indicated by red arrows), including chromatin condensation and nuclear fragmentation, were observed under the fluorescence microscope through Hoechst 33258 staining. Scale bar, $50 \mu \mathrm{m}$. (B) Cells were harvested, stained by Annexin V and PI, and subsequently analyzed by flow cytometry. (C) Apoptotic cell proportion was presented in the histogram. Data are presented as the mean \pm standard deviation. ${ }^{\text {P }}<0.05$ vs. the untreated control group. (D) Following incubation, expression level of cleaved-PARP, an apoptosis-associated protein, was assessed by western blotting. PARP, poly(ADP-ribose) polymerase; GBM, glioblastoma; PI, propidium iodide.

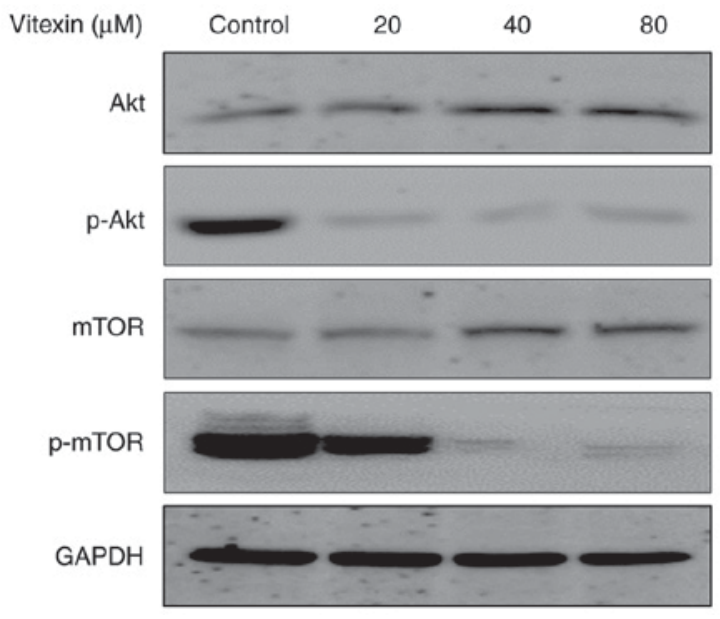

Figure 4. Vitexin inhibits the Akt/mTOR signaling pathway in GBM cells. Human GBM cells were treated with $0,20,40$ and $80 \mu \mathrm{M}$ vitexin for $24 \mathrm{~h}$. Expression levels of Akt, p-Akt, mTOR, p-mTOR were analyzed by western blotting. GBM, glioblastoma; Akt, RAC- $\alpha$ serine/threonine-protein kinase; p, phosphorylated; mTOR, mechanistic target of rapamycin kinase.

breaks. Levels of cleaved-PARP markedly increased following vitexin treatment. The aforementioned results demonstrated that vitexin induced cell apoptosis to inhibit cell proliferation.
Vitexin inhibits Akt/mTOR signaling pathway in human GBM cells. The aforementioned in vitro results indicated that vitexin treatment resulted in cell cycle arrest and cell apoptosis to inhibit cell viability in human GBM cells. To further investigate the underlying molecular mechanism of the anti-tumor effect of vitexin, the present study investigated the alterations in the Akt/mTOR signaling pathway. Western blotting was performed to measure the expression levels of Akt, mTOR, $\mathrm{p}-\mathrm{Akt}$, and p-mTOR proteins. The results demonstrated a dose-dependent decrease in phosphorylation of Akt and mTOR following treatment with vitexin (Fig. 4). These results indicated that vitexin inhibited activation of the Akt/mTOR signaling pathway, which may contribute to vitexin-induced cell cycle arrest and apoptosis.

\section{Discussion}

Natural products may serve as a source of flavonoids used for cancer prevention and treatment $(31,32)$. The flavonoid vitexin has previously gained attention due to its multiple pharmacological effects, including neuroprotective and anti-cancer properties. Vitexin was reported to markedly inhibit cell growth and induce cell apoptosis in a number of cancer cell lines, including hepatocellular carcinoma, oral and esophageal cancer $(33,34)$. 
However, whether it exhibits an effect on malignant GBM remains to be elucidated. The present study demonstrated that vitexin induced $\mathrm{G} 2 / \mathrm{M}$ cell cycle arrest and cell apoptosis by inhibiting Akt/mTOR signaling in human GBM cells.

The cell cycle is a precisely regulated process composed of G1, S, G2 and M phases. A successful transition between two phases serves a role in cell proliferation, particularly the $\mathrm{G} 2 / \mathrm{M}$ transition, which promotes the symmetric division of a cell (35). Disruption of the cell cycle is characteristic of cancer cells and results in uncontrolled cell proliferation. Therefore, the therapeutic aim of anti-cancer agents is to suppress cell proliferation, via an induction of $\mathrm{G} 2 / \mathrm{M}$ cell cycle arrest. The present study demonstrated that vitexin exhibited an effect on cell cycle progression by inducing cell cycle arrest at $\mathrm{G} 2 / \mathrm{M}$ transition phase. Compared with the control group, the percentage of cells at G2/M phase increased markedly, whereas the percentage of cells at G1 phase decreased.

Apoptosis is a result of cell cycle arrest and its rate may be used to predict the cytotoxicity of anti-cancer agents $(36,37)$. In the presence of pro-death stimuli, including cytotoxic agents, cells respond by initiating programmed death, characterized by certain detectable morphological alterations, including nuclear fragmentation, chromatin condensation, cell shrinkage, membrane blebbing and formation of apoptotic bodies $(26,38)$. The aforementioned morphological alterations serve as indicators of cell apoptosis. In the present study, morphological alterations indicated cell apoptosis following treatment with vitexin. A number of studies have demonstrated that cell apoptosis is triggered by caspase-dependent or caspase-independent pathways and the former is more common (39-42). In the caspase-dependent apoptotic process, caspases-3 and -8, and other downstream caspases are activated and subsequently cleave their common substrate, PARP, inducing apoptosis. Therefore, an increased expression level of cleaved-PARP is an indicator of cell apoptosis. Western blotting results demonstrated an increase in the expression level of cleaved-PARP in human GBM cells.

It has previously been demonstrated that certain signaling pathways are involved in the cell apoptosis process, including the PI3K/Akt/mTOR and mitogen-activated protein kinase pathways $(29,43,44)$. The present study investigated Akt/mTOR signaling due to its association with cell apoptosis in various cancer diseases (45). In the present study, phosphorylation of Akt and mTOR molecules was suppressed compared with the control group, which indicated negative regulation of Akt/mTOR signaling during vitexin-induced cell apoptosis.

In conclusion, the present study demonstrated that vitexin induced G2/M cell cycle arrest and cell apoptosis by inhibiting the Akt/mTOR signaling pathway in human GBM cells. To the best of the authors knowledge, the present study is the first to investigate anticancer effects of vitexin on human GBM cells and the underlying molecular mechanisms. Since flavonoids have been extensively used for cancer prevention and treatment, vitexin may in the future be used for GBM chemotherapeutic treatment, which requires further investigation.

\section{Acknowledgements}

The present study was supported by the Natural Science Foundation of Shandong Province (grant no. S20163721).

\section{References}

1. Kubelt C, Hattermann K, Sebens S, Mehdorn HM and Held-Feindt J: Epithelial-to-mesenchymal transition in paired human primary and recurrent glioblastomas. Int J Oncol 46: 2515-2525, 2015.

2. Torre LA, Bray F, Siegel RL, Ferlay J, Lortet-Tieulent J and Jemal A: Global cancer statistics, 2012. CA Cancer J Clin 65: 87-108, 2015.

3. Omuro A and DeAngelis LM: Glioblastoma and other malignant gliomas: A clinical review. JAMA 310: 1842-1850, 2013

4. Woehrer A, Bauchet L and Barnholtz-Sloan JS: Glioblastoma survival: Has it improved? Evidence from population-based studies. Curr Opin Neurol 27: 666-674, 2014

5. Cuddapah VA, Robel S, Watkins S and Sontheimer H: A neurocentric perspective on glioma invasion. Nat Rev Neurosci 15: 455-465, 2014.

6. Wirsching HG, Galanis E and Weller M: Glioblastoma. Handb Clin Neurol 134: 381-397, 2016.

7. Arévalo ÁST, Erices JI, Uribe DA, Howden J, Niechi I, Muñoz S, Martín RS and Monrás CAQ: Current therapeutic alternatives and new perspectives in glioblastoma multiforme. Curr Med Chem 24: 2781-2795, 2017.

8. Desjardins A, Rich JN, Quinn JA, Vredenburgh J, Gururangan S, Sathornsumetee S, Reardon DA, Friedman AH, Bigner DD and Friedman HS: Chemotherapy and novel therapeutic approaches in malignant glioma. Front Biosci 10: 2645-2668, 2005.

9. Gaitan E, Cooksey RC, Legan J and Lindsay RH: Antithyroid effects in vivo and in vitro of vitexin: A C-glucosylflavone in millet. J Clin Endocrinol Metab 80: 1144-1147, 1995.

10. He M, Min JW, Kong WL, He XH, Li JX and Peng BW: A review on the pharmacological effects of vitexin and isovitexin. Fitoterapia 115: 74-85, 2016.

11. Wang Y, Zhen Y, Wu X, Jiang Q, Li X, Chen Z, Zhang G and Dong L: Vitexin protects brain against ischemia/reperfusion injury via modulating mitogen-activated protein kinase and apoptosis signaling in mice. Phytomedicine 22: 379-384, 2015.

12. Che X, Wang X, Zhang J, Peng C, Zhen Y, Shao X, Zhang G and Dong L: Vitexin exerts cardioprotective effect on chronic myocardial ischemia/reperfusion injury in rats via inhibiting myocardial apoptosis and lipid peroxidation. Am J Transl Res 8: 3319-3328, 2016

13. An F, Yang G, Tian J and Wang S: Antioxidant effects of the orientin and vitexin in Trollius chinensis Bunge in D-galactose-aged mice. Neural Regen Res 7: 2565-2575, 2012.

14. Yang L, Yang ZM, Zhang N, Tian Z, Liu SB and Zhao MG: Neuroprotective effects of vitexin by inhibition of NMDA receptors in primary cultures of mouse cerebral cortical neurons. Mol Cell Biochem 386: 251-258, 2014.

15. He JD, Wang Z, Li SP, Xu YJ, Yu Y, Ding YJ, Yu WL, Zhang RX, Zhang HM and Du HY: Vitexin suppresses autophagy to induce apoptosis in hepatocellular carcinoma via activation of the JNK signaling pathway. Oncotarget 7: 84520-84532, 2016.

16. Yang SH, Liao PH, Pan YF, Chen SL, Chou SS and Chou MY: The novel p53-dependent metastatic and apoptotic pathway induced by vitexin in human oral cancer OC2 cells. Phytother Res 27: 1154-1161, 2013.

17. An F, Wang S, Tian Q and Zhu D: Effects of orientin and vitexin from Trollius chinensis on the growth and apoptosis of esophageal cancer EC-109 cells. Oncol Lett 10: 2627-2633, 2015.

18. Schwartz GK and Shah MA: Targeting the cell cycle: A new approach to cancer therapy. J Clin Oncol 23: 9408-9421, 2005.

19. Stewart ZA, Westfall MD and Pietenpol JA: Cell-cycle dysregulation and anticancer therapy. Trends Pharmacol Sci 24: 139-145, 2003.

20. Hanahan D and Weinberg RA: Hallmarks of cancer: The next generation. Cell 144: 646-674, 2011.

21. Kim G, Kim TH, Hwang EH, Chang KT, Hong JJ and Park JH: Withaferin A inhibits the proliferation of gastric cancer cells by inducing G2/M cell cycle arrest and apoptosis. Oncol Lett 14: 416-422, 2017.

22. Liberal J, Carmo A, Gomes C, Cruz MT and Batista MT: Urolithins impair cell proliferation, arrest the cell cycle and induce apoptosis in UMUC3 bladder cancer cells. Invest New Drugs: Jun 20, 2017 (Epub ahead of print).

23. Silva IT, Geller FC, Persich L, Dudek SE, Lang KL, Caro MS, Durán FJ, Schenkel EP, Ludwig S and Simões CM: Cytotoxic effects of natural and semisynthetic cucurbitacins on lung cancer cell line A549. Invest New Drugs 34: 139-148, 2016. 
24. King KL and Cidlowski JA: Cell cycle and apoptosis: Common pathways to life and death. J Cell Biochem 58: 175-180, 1995.

25. Kiraz Y, Adan A, Kartal Yandim M and Baran Y: Major apoptotic mechanisms and genes involved in apoptosis. Tumour Biol 37 8471-8486, 2016

26. Burgess DJ: Apoptosis: Refined and lethal. Nat Rev Cancer 13 79, 2013.

27. Germain M, Affar EB, D'Amours D, Dixit VM, Salvesen GS and Poirier GG: Cleavage of automodified poly(ADP-ribose) polymerase during apoptosis. Evidence for involvement of caspase-7. J Biol Chem 274: 28379-28384, 1999.

28. Granato M, Rizzello C, Gilardini Montani MS, Cuomo L, Vitillo M, Santarelli R, Gonnella R, D'Orazi G, Faggioni A and Cirone M: Quercetin induces apoptosis and autophagy in primary effusion lymphoma cells by inhibiting PI3K/AKT/mTOR and STAT3 signaling pathways. J Nutr Biochem 41: 124-136, 2017.

29. Ding L, Ding L, Wang S, Wang S, Wang W, Wang W, Lv P, Lv P, Zhao D, Zhao D, et al: Tanshinone IIA affects autophagy and apoptosis of glioma cells by inhibiting phosphatidylinositol 3-kinase/Akt/mammalian target of rapamycin signaling pathway. Pharmacology 99: 188-195, 2017.

30. Wang Y, Sun Y, Wu Y and Zhang J: Cucurbitacin E inhibits osteosarcoma cells proliferation and invasion through attenuation of PI3K/AKT/mTOR signaling. Biosci Rep: BSR20160165, 2016. doi: 10.1042/BSR20160165.

31. Li Y, Li S, Meng X, Gan RY, Zhang JJ and Li HB: Dietary natural products for prevention and treatment of breast cancer. Nutrients 9: E728, 2017.

32. Kou X, Fan J and Chen N: Potential molecular targets of ampelopsin in prevention and treatment of cancers. Anticancer Agents Med Chem: Apr 12, 2017 (Epub ahead of print).

33. Zhou J, Hu H, Long J, Wan F, Li L, Zhang S, Shi YE and Chen Y: Vitexin 6, a novel lignan, induces autophagy and apoptosis by activating the Jun N-terminal kinase pathway. Anticancer Drugs 24: 928-936, 2013.

34. Tan Z, Zhang Y, Deng J, Zeng G and Zhang Y: Purified vitexin compound 1 suppresses tumor growth and induces cell apoptosis in a mouse model of human choriocarcinoma. Int J Gynecol Cancer 22: 360-366, 2012.

35. Xia Y, Lei Q, Zhu Y, Ye T, Wang N, Li G, Shi X, Liu Y, Shao B, Yin T, et al: SKLB316, a novel small-molecule inhibitor of cell-cycle progression, induces $\mathrm{G} 2 / \mathrm{M}$ phase arrest and apoptosis in vitro and inhibits tumor growth in vivo. Cancer Lett 355 297-309, 2014
36. Bendale Y, Bendale V and Paul S: Evaluation of cytotoxic activity of platinum nanoparticles against normal and cancer cells and its anticancer potential through induction of apoptosis. Integr Med Res 6: 141-148, 2017.

37. Cao FJ, Zhu LF, Kuang Q, Li XQ, Zhou BH, Yang XJ and Zhou L: Cytotoxic activity, apoptosis induction and structure-activity relationship of 8-OR-2-aryl-3,4-dihydroisoquinolin-2-ium salts as promising anticancer agents. Bioorg Med Chem Lett 27: 55-60, 2017.

38. Ivanovska I, Muhoro CN and Irusta PM: Anti-tumor therapeutic molecules that target the programmed cell death machinery. Mini Rev Med Chem 6: 1033-1042, 2006.

39. Kolenko VM, Uzzo RG, Bukowski R and Finke JH: Caspase-dependent and -independent death pathways in cancer therapy. Apoptosis 5: 17-20, 2000.

40. Wang H, Zhang T, Sun W, Wang Z, Zuo D, Zhou Z, Li S, Xu J, Yin F, Hua Y and Cai Z: Erianin induces G2/M-phase arrest, apoptosis, and autophagy via the ROS/JNK signaling pathway in human osteosarcoma cells in vitro and in vivo. Cell Death Dis 7 : e2247, 2016.

41. Croce CM and Reed JC: Finally, an apoptosis-targeting therapeutic for cancer. Cancer Res 76: 5914-5920, 2016.

42. Su Z, Yang Z, Xu Y, Chen Y and Yu Q: Apoptosis, autophagy, necroptosis, and cancer metastasis. Mol Cancer 14: 48, 2015.

43. Huang G, Zou B, Lv J, Li T, Huai G, Xiang S, Lu S, Luo H, Zhang Y, Jin Y and Wang Y: Notoginsenoside R1 attenuates glucose-induced podocyte injury via the inhibition of apoptosis and the activation of autophagy through the PI3K/Akt/mTOR signaling pathway. Int J Mol Med 39: 559-568, 2017.

44. Ko JH, Lee JH, Jung SH, Lee SG, Chinnathambi A, Alharbi SA, Yang WM, Um JY, Sethi G and Ahn KS: 2,5-Dihydroxyacetophenone induces apoptosis of multiple myeloma cells by regulating the MAPK activation pathway. Molecules 22: E1157, 2017.

45. Fulda S: Synthetic lethality by co-targeting mitochondrial apoptosis and PI3K/Akt/mTOR signaling. Mitochondrion 19: 85-87, 2014. 